\title{
VIÉS DE GÊNERO NA ESCOLHA PROFISSIONAL NO BRASIL
}

\author{
Maria Fernanda Pessoa ${ }^{1}$ \\ Daniela Verzola Vaz II \\ Diego Camargo Botassio III \\ I Universidade Federal de São Paulo (Unifesp), Osasco (SP), Brasil; maria.fernandapessoa5@gmail.com \\ II Universidade Federal de São Paulo (Unifesp), Osasco (SP), Brasil; daniela.vaz@unifesp.br \\ IIIMinistério da Economia, Brasília (DF), Brasil; diegocbotassio@gmail.com
}

\section{Resumo}

Este artigo analisa a segregação por sexo nos cursos presenciais de ensino superior brasileiro, investigando suas causas, características e evolução no tempo. Para tanto, são calculados indicadores sintéticos de segregação com base nas edições de 2000 e 2017 do Censo da Educação Superior. Nesse período, a queda no grau geral de segregação foi tímida e resultou de dois movimentos opostos: a redução da estratificação de homens e mulheres entre as grandes áreas de conhecimento, contrabalançada pelo aumento da segregação dentro delas. Assim, ao nível mais agregado de análise, há tendência à integração por sexo dos campos de estudo. Porém, em se tratando de carreiras específicas, persistem os estereótipos de gênero, com segmentação entre cursos tipicamente masculinos e femininos.

ESTEREÓTIPO • RELAÇÕES DE GÊNERO • ENSINO SUPERIOR • ESCOLHA PROFISSIONAL

\section{GENDER BIAS IN CAREER CHOICE IN BRAZIL}

\section{Abstract}

This article analyzes sex segregation in in-person higher education programs in Brazil by investigating its causes, characteristics and evolution over time. To that end, synthetic indicators of segregation are calculated based on the 2000 and 2017 editions of the Censo da Educação Superior [Higher Education Census]. During this period, the decrease in the overall degree of segregation was subtle, as a result of two opposite movements: the reduction in the stratification of men and women between the major areas of knowledge, which is offset by increased segregation within them. Thus, at the most aggregate level of analysis, there is a tendency towards sex integration in the fields of study. However, when it comes to specific careers, gender stereotypes persist, with separation between typically "male" and "female" programs. 


\section{SESGO DE GÉNERO EN LA ELECCIÓN PROFESIONAL EN BRASIL}

\section{Resumen}

Este artículo analiza la segregación sexual en las carreras de graduación en modalidad presencial de la enseñanza superior en Brasil, investigando sus causas, características y evolución en el tiempo. Para eso son calculados índices sintéticos de segregación con datos de las ediciones de 2000 y 2017 del Censo de la Educación Superior. En este período la caída en el nivel general de segregación fue tímida y resultante de dos movimientos opuestos: la reducción de la estratificación de hombres y mujeres entre las grandes áreas del conocimiento, contrabalanceada por el aumento en la segregación dentro de esas ramas. Así, al nivel más agregado de análisis, hay una tendencia a la integración por sexo entre los campos de estudio. Sin embargo, cuando se trata de carreras específicas, persisten los estereotipos de género, con una segmentación entre las carreras típicamente masculinas y femeninas.

ESTEREOTIPO • RELACIONES DE GÉNERO • ENSEÑANZA SUPERIOR • ELECCIÓN PROFESSIONAL

\section{BIAIS DE GENRE DANS LE CHOIX PROFESSIONNEL AU BRÉSIL \\ Résumé}

Cet article analyse la ségrégation des sexes dans l'enseignement supérieur brésilien, tout en examinant ses causes, caractéristiques et son évolution dans le temps. À cette fin, des indicateurs synthétiques de ségrégation sont calculés en utilisant les éditions de 2000 et 2017 du Censo da Educação Superior [Recensement de l'Éducation Supérieure]. Dans cette période, la chute dans le degré général de ségrégation a été timide et a résulté de deux mouvements opposés: la réduction de la stratification des hommes et femmes entre les grands domaines du savoir, contrecarrée par l'incrément de la ségrégation dans ces-domaines. Donc au niveau plus agrégé d'analyse, il y a une tendance à l'intégration par sexe des champs d'étude au niveau des carrières, les stéréotypes de genre perdurent, avec une segmentation entre les métiers typiquement masculins et féminins.

STEREOTYPES • RAPPORTS DE GENRE • ENSEIGNEMENT SUPÉRIEUR • CHOIX PROFESSIONNEL 

matriculados no ensino superior no Brasil, impulsionada por programas do Governo Federal na primeira década do milênio que compreendiam maior oferta de vagas em universidades públicas e concessão de bolsas e financiamentos em instituições privadas. Entre 2000 e 2017, houve um aumento de aproximadamente $141 \%$ no número de alunos matriculados nos cursos presenciais de graduação.

Apesar de o caminho trilhado pelas mulheres na educação superior ter sido conturbado devido aos condicionantes sociais, nas últimas décadas houve uma reversão do hiato de sexo nessa esfera de ensino (Alves, 1994; Beltrão \& Alves, 2009; Beltrão \& Teixeira, 2005). As universidades, que previamente formavam um ambiente dominado quase exclusivamente por homens, passaram a ser ocupadas majoritariamente por mulheres.

Contudo, a maior participação feminina no ambiente universitário não significou uma igualdade na representatividade nos diferentes cursos, uma vez que há uma perpetuação dos estereótipos de gênero, que se manifestam na sobrerrepresentação feminina em cursos ligados à educação e aos cuidados de terceiros e na predominância masculina em cursos que valorizam o pensamento lógico e a competitividade (Barreto, 2014; Beltrão \& Teixeira, 2005).

A literatura aponta que, no mercado de trabalho, as ocupações predominantemente femininas oferecem, em média, remunerações inferiores às observadas nas ocupações masculinas, mesmo quando controlado o nível de escolaridade (Oliveira, 2003; Fresneda, 2007; Madalozzo, 2010). Assim, é possível constatar que a segregação por sexo no ensino superior apresenta impactos socioeconômicos posteriores, pois ocasiona diferenciais de remuneração entre homens e mulheres ao longo da vida profissional.

Este estudo investiga a segregação por sexo nos cursos universitários presenciais no Brasil, incorporando análises intertemporais, bem como comparações regionais, com o intuito de averiguar, em âmbito nacional, o comportamento desse fenômeno. Pretende-se, em particular, verificar se o grau de segregação tem se reduzido no período da análise. Para tanto, são utilizados os microdados do Censo da Educação Superior, conduzido pelo Instituto Nacional de Estudos e Pesquisas Educacionais Anísio Teixeira (Inep), a fim de calcular medidas de segregação, tais como o índice de Gini e o de dissimilaridade. Além desses indicadores tradicionais, utiliza-se o índice raiz quadrada, proposto por Hutchens (2001), que permite decompor a segregação (total) em duas parcelas: uma referente à segregação entre áreas de conhecimento, e outra correspondente a uma soma ponderada dos níveis de segregação nessas áreas. Para efeitos de comparação, são utilizadas as edições de 2000 e 2017 do Censo.

Análises da representatividade feminina nos cursos superiores no Brasil não são infrequentes, porém elas se pautam no cálculo da proporção observada de mulheres para cada área do conhecimento ou então em carreiras isoladas. Esse tipo de análise não permite obter um valor único para o grau geral de segregação observada no ensino superior no país. O cálculo de medidas sintéticas, já usualmente empregadas em análises do mercado de trabalho, contribui para aprofundar a compreensão da desigualdade da representação feminina nas carreiras universitárias. Cumpre notar que não foram encontrados estudos prévios na literatura nacional que aplicassem medidas sintéticas de segregação aos dados do Censo da Educação Superior, fazendo ainda um comparativo entre essas medidas e entre os resultados de suas edições.

Este trabalho está organizado em cinco seções, sendo a primeira esta introdução. Na segunda seção, foram abordadas as contribuições dos principais autores acerca do tema. Na terceira seção, explicam-se os dados e a metodologia adotada. A quarta seção traz os resultados e a análise. E a quinta seção discute as implicações e caminhos futuros para essa linha de pesquisa. 


\section{Revisão de literatura}

Durante séculos, a construção social da relação entre os gêneros resultou na formação de dois grupos com traços antagônicos e hierarquizados: mulheres e homens, estes em posição de dominação. O papel da mulher foi forjado no âmbito reprodutivo, isto é, domiciliar, ao passo que as atividades extradomésticas - vistas com mais prestígio - eram dominadas, de modo geral, pelos homens (Alves, 1994; Kergoat, 2009).

Isso levou ao que a literatura reconhece como a divisão sexual do trabalho, ou seja, uma "partilha" dasatividades etarefas desempenhadas por homens e mulheres. Segundo Melo e Castilho(2009), o trabalho doméstico (ou reprodutivo) - que não é reconhecido pela sociedade como trabalho - é considerado, em grande medida, responsabilidade feminina. Por outro lado, segundo as autoras, o trabalho produtivo, que é, de fato, reconhecido e remunerado pelo capital, apresenta uma maior participação masculina, uma vez que a inserção da mulher no mercado de trabalho é um fenômeno relativamente recente.

Historicamente, como os homens detinham o papel de provedores, atuando na esfera produtiva, eles obtinham maior acesso à educação formal visando à especialização no mercado de trabalho, enquanto as mulheres, geralmente, eram ensinadas a realizar tarefas domésticas e a cuidar dos outros - principalmente de crianças - para desempenhar seu papel de mãe e esposa. Dessa forma, a educação brasileira sempre foi focada nos homens, desatendendo as mulheres. Essa situação se evidenciava pelo hiato de gênero na educação, isto é, pelas diferenças sistemáticas nos níveis de escolaridade de homens e mulheres (Beltrão \& Alves, 2009).

No século XIX, surgiram as primeiras instituições de ensino básico voltadas para as mulheres. Essas, no entanto, eram diferentes das masculinas, pois suas diretrizes pautavam-se no fortalecimento do papel da mulher como mãe e esposa. Assim, o sistema educacional brasileiro apresentou, desde sua gênese, uma dualidade e segmentação de gênero (Beltrão \& Teixeira, 2005).

Mesmo quando conseguiam concluir os estudos básicos, as mulheres deparavam-se com dificuldades e barreiras à entrada no ensino superior, pois, a despeito da viabilização de seu ingresso nas faculdades e escolas de ensino superior, datada de 1881, por decreto imperial, os cursos básicos não as habilitavam para isso. Segundo dados do Instituto Brasileiro de Geografia e Estatística (IBGE), a porcentagem de mulheres matriculadas nos cursos superiores entre 1907 e 1912 era inferior a 1,5\% (Beltrão \& Alves, 2009).

No entanto, com o passar do século XX, as mulheres foram ganhando espaço no cenário educacional brasileiro. Com a Lei de Diretrizes e Bases da Educação (LDB), de 1961, o magistério que à época era cursado pela maioria das mulheres - foi reconhecido como equivalente a um curso de grau médio, possibilitando aos seus egressos prestarem vestibulares. A convergência de transformações sociais com a luta do movimento feminista permitiu que, a partir dos anos de 1980, houvesse uma reversão do hiato de gênero na educação superior, com as mulheres tornando-se maioria nesse nível de ensino. Isso se acentuou com as mudanças ocorridas na Nova República, período em que houve uma expansão do ensino superior (Beltrão \& Alves, 2009).

No entanto, apesar de as mulheres atualmente serem a maioria dos estudantes nas universidades, nota-se que uma parte considerável delas concentra-se em cursos relacionados às atividades de cuidado e educação - como Pedagogia, Enfermagem e Psicologia -, o que reflete seu papel estereotipado na sociedade.

O senso comum entende características como racionalidade e competitividade como pertinentes ao gênero masculino, ao passo que características como compaixão, empatia e submissão são consideradas essencialmente femininas (Barreto, 2014). Esses estereótipos moldam as relações de ocupações e carreiras, uma vez que no mercado de trabalho as habilidades mais valorizadas são as ditas masculinas, e, para a realização de cuidados da família e do lar, as características consideradas femininas são mais valorizadas. 
O papel social atribuído às mulheres reflete-se, assim, nas atividades laborais por elas desempenhadas, que, como dito anteriormente, têm como foco o cuidado e a educação. Os atributos culturalmente vinculados ao gênero feminino inibem sua atuação em atividades mais técnicas e científicas. Dessa maneira, as mulheres são excluídas ou se excluem de ambientes e profissões associadas à personalidade masculina - vista como mais ativa, independente e forte -, e acabam interiorizando as expectativas a respeito da sua função na sociedade, consolidando, dessa forma, a divisão entre atividades masculinas e femininas (Chabaud-Rychter \& Gardey, 2009).

Estudos no campo da Psicologia Social revelam que os estudantes do ensino básico tendem a escolher carreiras em que acreditem que serão bem-sucedidos e não terão muitas dificuldades. Frequentemente é propagada a ideia de que as áreas de Ciências, Tecnologia, Engenharia e Matemática $\left(\mathrm{STEM}^{1}\right)$ são difíceis, e, portanto, devem ser ocupadas apenas por pessoas consideradas brilhantes qualidade associada à masculinidade. Há, ainda, a crença de que essas áreas são apropriadas para grupos sociais específicos, a saber, homens de ascendência europeia. Além disso, há a visão cultural de que as pessoas que ocupam essas áreas são introvertidas e pouco atraentes fisicamente. $\mathrm{O}$ fato de as meninas muitas vezes não se identificarem com esses estereótipos faz com que elas não se imaginem trilhando tais carreiras e passem a ter uma percepção negativa de si mesmas, tornando-se inseguras na realização de atividades de Matemática e outras ciências exatas. Por acreditarem que não sejam capazes de ter bons resultados nas ciências exatas e que não terão uma carreira de sucesso caso consigam se graduar nessas áreas, elas costumam optar por carreiras mais alinhadas aos estereótipos femininos (González-Pérez et al., 2020; Shin et al., 2016; Herrmann et al., 2016).

A interiorização dessas expectativas e estereótipos pode ser exemplificada pela pesquisa realizada por Queiroz et al. (2014) com estudantes do sexo feminino em uma escola pública. Por meio de questionários respondidos pelas estudantes, traçou-se um perfil a respeito da preferência por carreiras e disciplinas ministradas no currículo base do ensino brasileiro. Com essa pesquisa, as autoras concluem que a reafirmação de estereótipos de gênero no ambiente educacional - como as frequentes declarações de que meninas não têm facilidade para cálculo - contribui para que elas internalizem o ideal de que seriam mais aptas para cursos com viés mais humano do que técnico e científico, por, muitas vezes, serem induzidas a crer que não tenham a capacidade analítica que essas últimas áreas costumam demandar.

Ao estudar as diferentes escolhas entre meninos e meninas no sistema educacional francês, Rapoport e Thibout (2018) concluem que ambos os sexos consideram os retornos esperados no mercado de trabalho ao realizar escolhas educacionais. No entanto, as percepções que os estudantes têm a respeito dos resultados obtidos em avaliações são diferentes para os sexos. Enquanto os meninos costumam considerar bons resultados obtidos nos testes de disciplinas exatas como um indicativo de que devam seguir carreiras que envolvam maior capacidade analítica, as meninas tendem a subestimar esses resultados - mesmo quando alcançam notas altas - e optam por carreiras na área de humanas. Uma possível interpretação das autoras desse fenômeno diz respeito à percepção que as meninas costumam ter de serem menos capazes do que os meninos (da mesma forma que os meninos costumam ter a percepção de que são mais capazes que as meninas), especialmente nas Ciências Exatas e Tecnológicas.

Assim, apesar de meninos e meninas terem, relativamente, acesso igual à educação, a escolha das carreiras é diferenciada, pois meninas escolhem majoritariamente cursos ligados aos cuidados e ao ensino, bem como às Ciências Humanas. Esses cursos são vistos como de menor notoriedade do que aqueles majoritariamente masculinos, e normalmente estão associados a salários inferiores, o que ajuda a explicar, em parte, as diferenças salariais entre homens e mulheres no mercado de trabalho (Beltrão $\&$ Teixeira, 2005). 
Analisando a segregação por gênero sob a ótica do mercado de trabalho, Fresneda (2007) busca elucidar as diferenças salariais entre homens e mulheres pela segregação ocupacional, que, segundo a autora, pode ser explicada pela internalização de estereótipos de gênero, que induz as mulheres a seguirem carreiras consideradas mais femininas. Utilizando a edição de 2004 da Pesquisa Nacional por Amostra de Domicílios (Pnad), Fresneda (2007) mostra que, de fato, há carreiras majoritariamente ocupadas por mulheres, e que, em média, apresentam $63 \%$ do salário/hora das ocupações masculinas. O estudo conclui, entre outros resultados, que, no Brasil, as mulheres estão concentradas em ocupações que remuneram menos em comparação aos homens.

De acordo com Madalozzo e Artes (2017, p. 1), “. . . um dos mais importantes efeitos da existência de segregação ocupacional é o seu impacto nas diferentes remunerações recebidas por homens e mulheres ao longo de suas carreiras". Os autores buscam analisar os perfis dos indivíduos que optam por diferentes carreiras, utilizando os microdados da edição de 2013 da Pnad. Para tanto, as ocupações são agrupadas segundo sua composição por sexo, resultando em três categorias: femininas, com, no mínimo, $60 \%$ de mulheres; masculinas, isto é, com mais de 60\% de homens; e integradas, que apresentam distribuição relativamente equânime entre os sexos. $\mathrm{O}$ estudo conclui que, em média, as mulheres recebem remuneração inferior aos homens. Todavia, o impacto nos diferenciais de rendimento é reduzido quando as mulheres exercem as tradicionais profissões imperiais (Direito, Engenharia e Medicina) e/ou optam por um número maior de horas trabalhadas.

Cumpre notar que o fenômeno da segregação ocupacional por sexo e seu consequente impacto nas remunerações não é restrito ao Brasil. Analisando a ascensão feminina no mercado de trabalho estadunidense, Bergmann (2005) aponta que, anteriormente, o papel da mulher na economia era definido pela realização de tarefas domésticas e cuidados de crianças, ao passo que os homens, responsáveis por manter financeiramente o lar com trabalhos remunerados, não participavam da realização de tarefas domésticas. Para a autora, a diferenciação entre atividades masculinas e femininas é apresentada desde a infância e absorvida pelos indivíduos como algo natural. Essa noção de que o sexo determina quais atividades devem ser desempenhadas por homens ou mulheres é mantida na fase adulta e serve como forma de reafirmar a masculinidade e a feminilidade.

Por muitos séculos as mulheres estadunidenses foram privadas de atividades produtivas. Contudo, a partir do século XIX, passaram a integrar a força de trabalho gradativamente, de modo que, a partir da década de 1970, aquelas que buscavam trabalhos remunerados eram maioria em relação às que mantinham dedicação exclusiva ao lar. Em 1870, apenas $14 \%$ das mulheres com idade para trabalhar estavam empregadas - a maioria ocupando cargos de empregadas domésticas ou atuando em fábricas com baixos salários. Já em 2001, essa proporção passou a ser de 60\%, e as mulheres ocupavam também diversos outros cargos (Bergmann, 2005).

Ainda segundo Bergmann (2005), apesar de passarem a integrar massivamente a força de trabalho estadunidense, as mulheres ainda sofrem discriminação no mercado de trabalho - embora essa prática tenha se tornado ilegal com a Lei dos Direitos Civis de 1964. Mulheres continuam sendo excluídas de profissões ocupadas majoritariamente por homens, sendo forçadas a recorrer a oportunidades em profissões associadas a tarefas tipicamente femininas. Essas profissões, no entanto, oferecem remunerações inferiores às ofertadas nas áreas ocupadas por homens. Por acreditarem que não serão bem-sucedidas em áreas dominadas por homens, muitas mulheres sequer tentam ingressar nelas. As mulheres que conseguem, todavia, adentrar profissões consideradas masculinas lidam com problemas como assédio moral e sexual, além de salários inferiores aos de homens com mesmo cargo e menos oportunidades de promoção (Bergmann, 2005).

Conforme se vê, portanto, há relativo consenso na literatura a respeito da segregação ocupacional por sexo. A literatura aponta, ainda, que as profissões ditas femininas oferecem, em média, remunerações inferiores às masculinas, ocasionando, assim, diferenciais de remuneração por sexo no 
mercado de trabalho. Esta pesquisa se propõe a aprofundar a análise do grau de segregação por sexo no ensino superior brasileiro, investigando seu comportamento intertemporal, bem como suas diferenças regionais. Para tanto, apoia-se em medidas sintéticas mais refinadas do grau de segregação, a serem apresentadas na próxima seção.

\section{Material e métodos}

Para a realização deste estudo foram utilizados os microdados do Censo da Educação Superior, conduzido pelo Inep. Trata-se de uma pesquisa de abrangência nacional e periodicidade anual que investiga instituições de educação superior, reunindo informações a respeito de seus cursos de graduação e sequenciais, como número de vagas ofertadas, de ingressantes, de concluintes, de docentes, de funcionários técnico-administrativos, entre outras. ${ }^{2}$

Os dados analisados foram os referentes aos estudantes matriculados em cursos presenciais de graduação das edições de 2000 e 2017 (Inep, 2000, 2017) - sendo aquela a mais antiga que possui comparabilidade com a de 2017 no que se refere à metodologia de classificação dos cursos em áreas e subáreas de conhecimento.

$\mathrm{Na}$ análise descritiva preliminar, verificaram-se quais cursos e áreas têm maior e menor representação feminina dentre os 20 cursos com maior número de alunos matriculados. Para isso, calculou-se o Índice de Paridade de Gênero (IPG), que é a razão entre a quantidade de mulheres e a de homens em um dado curso, de modo que, se seu resultado for inferior a 1, há disparidade em favor dos homens, e, se for superior a 1 , há disparidade em favor das mulheres.

Para analisar o grau de segregação propriamente dito, utilizaram-se três medidas tradicionais na literatura: o índice de dissimilaridade (Jahn et al., 1947), o índice de Gini para segregação (Duncan \& Duncan, 1955) e o índice raiz quadrada (Hutchens, 2001). A apresentação que se segue está baseada em Hoffmann et al. (2019), porém, em lugar de categorias ocupacionais, foram considerados os diferentes cursos de graduação presencial.

Para um universo de $n$ cursos, $H_{i}$ e $M_{i}$ são, respectivamente, o número de homens e de mulheres no $i$-ésimo curso $(i=1, \ldots, n)$. Dessa forma, $H$ e $M$ indicam o número total de homens e mulheres na população de estudantes $\left(H=\sum_{i=1}^{n} H_{i}\right.$ e $\left.M=\sum_{i=1}^{n} M_{i}\right)$. Assim, a fração do total de homens no $i$-ésimo curso é $h_{i}=H_{i} / H$, e $m_{i}=M_{i} / M$ é a respectiva fração do total de mulheres no curso.

Admitindo que os cursos sejam ordenados segundo valores crescentes do IPG, de maneira que $M_{1} / H_{1} \leq M_{2} / H_{2} \leq \ldots \leq M_{n} / H_{n}$, define-se a proporção acumulada de homens e de mulheres até a $i$-ésima categoria respectivamente como $p_{i}=\sum_{j=1}^{i} h_{j}$ e $\Phi_{i}=\sum_{j=1}^{i} m_{j}$.

Para efeito de notação, pode-se definir $\left(p_{0}, \Phi_{0}\right)=(0,0)$. Assim, a curva de segregação, definida por Duncan e Duncan (1955), é obtida unindo-se, consecutivamente, pontos de coordenadas $\left(p_{i}, \Phi_{i}\right)$ para $i=0,1, \ldots, n$. Se não houver segregação, a curva terá o formato da bissetriz do primeiro quadrante, conforme se vê na Figura 1, a seguir. Do contrário, isto é, havendo cursos com predominância masculina e outros com predominância feminina, essa curva ficará abaixo da bissetriz do primeiro quadrante, tendo como limites os pontos $(0,0)$ e $(1,1)$. Considera-se $\alpha$ como sendo a área delimitada pela curva de segregação e a bissetriz do primeiro quadrante, de forma que seu valor varia entre 0 (quando a segregação é inexistente) e 0,5 (quando a segregação é total).

2 Segundo o site do Inep, os dados são coletados por meio do preenchimento dos questionários por parte das Instituições de Ensino Superior, além da importação de dados do Sistema e-MEC - base de dados relativa à educação superior brasileira. 


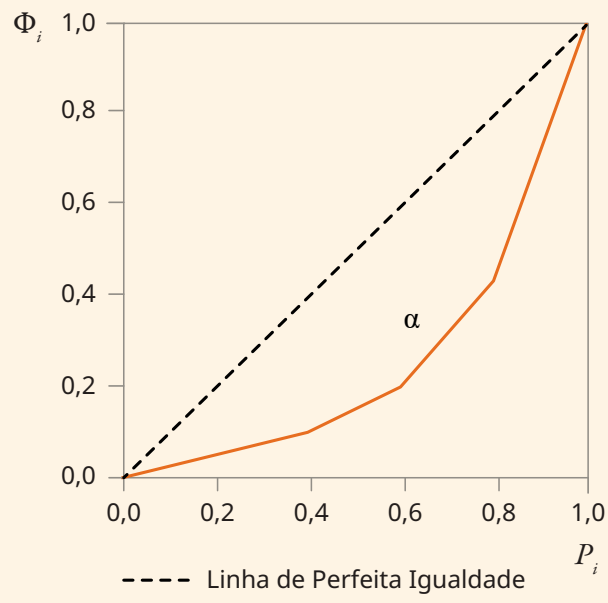

Fonte: Elaboração dos autores com base em Hoffmann et al. (2019, p. 307).

O índice de Gini para segregação é definido pela razão entre $\alpha$ e seu valor máximo, de modo que $G_{s}=\alpha / 0,5=2 \alpha$. Assim, é possível verificar que $0 \leq G_{s} \leq 1$. Quando o Gini é zero, não há segregação, isto é, em cada curso, a proporção de mulheres no total de matriculados é a mesma da proporção de homens. No outro extremo, quando o Gini é 1, a segregação é máxima, isto é, os cursos são frequentados exclusivamente por homens ou por mulheres. Vale notar que, segundo Hoffmann et al. (2019), esse índice também pode ser calculado mediante a expressão

$G_{s}=1-\sum_{i=1}^{n}\left(\Phi_{i}+\Phi_{i-1}\right) h i$

O índice de dissimilaridade, proposto por Jahn et al. (1947), é, sem dúvida, a medida de segregação mais utilizada na literatura. Sua expressão matemática é

$D=\frac{1}{2} \sum_{i=1}^{n}\left|h_{i}-m_{i}\right|$

Entre as vantagens da adoção do índice de dissimilaridade está a possibilidade de uma interpretação concreta de seu valor, já que ele indica a proporção de mulheres e de homens que deveriam mudar de curso para eliminar a segregação por sexo (Anker, 1998, p. 75). Uma desvantagem, porém, é que ele é sensível apenas a redistribuições que envolvam a transição de uma mulher de uma categoria predominantemente feminina para outra predominantemente masculina, e vice-versa. Assim, ele não capta os efeitos decrescentes sobre seu valor quando uma mulher pertencente a um curso "feminino" troca de lugar com um homem também pertencente a um curso "feminino", que, no entanto, possua menor participação relativa de mulheres. Dessa forma, o índice de Gini apresenta uma vantagem em relação ao índice de dissimilaridade, uma vez que é sensível a qualquer mudança na distribuição que resulte em menor ou maior segregação (Vaz \& Hoffmann, 2011).

Além dos índices de Gini e de dissimilaridade, também foi calculado o índice raiz quadrada, proposto por Hutchens (2001):

$$
I=1-\sum_{i=1}^{n} \sqrt{h_{i} m_{i}}
$$


Assim como os índices de Gini e dissimilaridade, seu limite inferior é 0 - caso extremo de ausência de segregação -, e seu valor máximo é 1 - caso de extrema segregação.

Uma propriedade interessante do índice raiz quadrada é que ele é aditivamente decomponível, isto é, a segregação (total) pode ser decomposta em duas parcelas: uma referente à segregação entre agrupamentos de cursos, e outra que corresponde a uma soma ponderada das medidas de segregação nesses grupamentos. Considere-se que os $n$ cursos possam ser agrupados em $k$ grupos. Essa classificação dos cursos em grupos deve obedecer a algum critério de similaridade preestabelecido, de modo que todos os cursos sejam classificados em apenas um grupo. Neste trabalho, o critério de similaridade é a proximidade do conhecimento, e os grupos correspondem às áreas da classificação adotada pelo Inep, que é uma adaptação da Classificação Internacional Padronizada da Educação (ISCED ${ }^{3}$ ).

Se $I_{g}$ indica a segregação dentro da $g$-ésima área $(g=1, \ldots, k)$, e $h_{g}$ e $m_{g}$ são as participações de homens e mulheres da $g$-ésima área nos totais de cada sexo, respectivamente, a decomposição aditiva do índice raiz quadrada é: ${ }^{4}$

$$
I=\sum_{g=1}^{k} I_{g} \sqrt{h_{g} m_{g}}+\left(1-\sum_{g=1}^{k} \sqrt{h_{g} m_{g}}\right)
$$

O termo do lado esquerdo da equação (4) é a segregação total (medida ao nível do curso). O primeiro termo do lado direito da expressão é a segregação nas áreas de conhecimento. Essa parcela é constituída pela soma das medidas de segregação nas áreas $(I)$, ponderadas pelos fatores $\sqrt{h_{g} m_{g}}$. O segundo termo do lado direito da equação é a segregação entre as áreas. Note que a decomposição (4) somente é válida quando são considerados unicamente os cursos pertencentes à $g$-ésima área para o cálculo da medida $I_{g}$. Cumpre notar que o índice de dissimilaridade não atende à propriedade de adição decomponível, ao passo que o índice de Gini somente a satisfaz quando as áreas são criadas com base na ordenação dos cursos segundo as razões $M_{i} / H_{i}$.

Para ilustrar as propriedades dos índices apresentados, tome-se como exemplo prático uma situação hipotética envolvendo a distribuição de alunos em quatro cursos distintos em três momentos, conforme a Tabela 1 , a seguir.

\section{TABELA 1}

\section{EXEMPLO DE UMA ALTERAÇÃO NA DISTRIBUIÇÃO DE HOMENS E MULHERES EM CURSOS DE NÍVEL SUPERIOR}

\begin{tabular}{|c|c|c|c|c|c|c|c|c|c|}
\hline \multirow{2}{*}{ Curso } & \multicolumn{3}{|c|}{$1^{\circ}$ momento } & \multicolumn{3}{|c|}{$2^{\circ}$ momento } & \multicolumn{3}{|c|}{$3^{\circ}$ momento } \\
\hline & Mulheres & Homens & IPG & Mulheres & Homens & IPG & Mulheres & Homens & IPG \\
\hline Engenharia Civil & 2 & 6 & 0,33 & 3 & 6 & 0,50 & 3 & 6 & 0,50 \\
\hline Direito & 4 & 2 & 2,00 & 3 & 2 & 1,50 & 3 & 2 & 1,50 \\
\hline Psicologia & 7 & 3 & 2,33 & 7 & 3 & 2,33 & 5 & 3 & 1,67 \\
\hline Pedagogia & 8 & 3 & 2,67 & 8 & 3 & 2,67 & 10 & 3 & 3,33 \\
\hline Total de estudantes & 21 & 14 & 1,50 & 21 & 14 & 1,50 & 21 & 14 & 1,50 \\
\hline Dissimilaridade & & 0,3333 & & & 0,2857 & & & 0,2857 & \\
\hline Gini & & 0,3639 & & & 0,3367 & & & 0,3776 & \\
\hline Raiz quadrada & & 0,0800 & & & 0,0567 & & & 0,0644 & \\
\hline
\end{tabular}

Fonte: Elaboração dos autores.

3 Do inglês, "International Standard Classification of Education".

4 Para detalhes sobre como derivar a expressão (4) com base na (3), ver Botassio (2017, pp. 37-39) e Hoffmann et al. (2019, pp. 312-314). 
Em um primeiro momento, apenas o curso de Engenharia Civil apresenta disparidade de sexo em favor dos homens, com IPG igual a 0,33; isto é, para cada três homens matriculados em Engenharia Civil, há uma mulher matriculada nesse curso. Os outros cursos da tabela apresentam disparidade em favor das mulheres, ainda que em graus diferentes. O curso de Pedagogia é o mais feminino, com quase três mulheres matriculadas para cada homem. Esse curso é seguido por Psicologia, com IPG igual a 2,33, e Direito, com IPG igual a 2,00.

Mantendo constante o total de alunos matriculados e a distribuição de homens nos quatro cursos, se em um segundo momento uma das mulheres matriculadas em Direito se transferir para Engenharia Civil, a disparidade em ambos os cursos será reduzida. Note que os três índices de segregação diminuem nesse segundo momento, comparado ao primeiro. Se, ainda, em momento posterior, houver uma realocação entre as mulheres dos outros cursos já femininos, de forma que duas estudantes de Psicologia sejam transferidas para Pedagogia, a disparidade em favor das mulheres se elevará nesse segundo curso, porém se reduzirá para Psicologia. No entanto, o índice de dissimilaridade não é sensível a essa transferência (permanece igual a 0,2857), mesmo que os índices de Gini e raiz quadrada indiquem aumento da segregação entre o segundo e terceiro momento.

Por outro lado, os índices de Gini e raiz quadrada são sensíveis a transferências entre quaisquer cursos, independentemente da predominância masculina ou feminina. Assim, esses índices são capazes de captar também o aumento na participação de mulheres em uma área que, apesar de já ser ocupada majoritariamente por mulheres, não era tão díspar - e posteriormente passa a ser. Esse exemplo evidencia a possibilidade de o índice de dissimilaridade apresentar redução na segregação, e, simultaneamente, o índice de Gini mostrar uma estagnação - ou até mesmo uma piora. Conforme ilustrado no exemplo hipotético da Tabela 1, comparando o primeiro e o terceiro momento, houve diminuição da segregação conforme os índices de dissimilaridade e raiz quadrada, porém houve aumento da segregação segundo o índice de Gini. Esse exemplo ilustra a importância de utilizar diferentes medidas de segregação em análises empíricas.

\section{Resultados e discussão}

Na edição de 2000 do Censo da Educação Superior, verificou-se a existência de 359 cursos presenciais de graduação e 2,69 milhões de estudantes matriculados, dos quais $56,2 \%$ eram mulheres. Essa proporção evidencia a continuidade do processo de reversão do hiato de gênero na educação, que se iniciou na segunda metade do século XX, conforme assinalado por Beltrão e Alves (2009).

Na Tabela 2, inspirada nos quadros 2 e 3 de Ricoldi e Artes (2016, pp. 157-165), foram selecionados os 20 cursos com maior número de alunos matriculados (considerando ambos os sexos) em 2000, ranqueados em ordem decrescente. Foi também destacado o ranking de cada um desses cursos em separado para cada sexo, com o intuito de comparar a participação de homens e mulheres. 
TABELA 2

DISTRIBUIÇÃO DE ESTUDANTES DE GRADUAÇÃO PRESENCIAL, NOS 20 CURSOS MAIS FREQUENTES, POR SEXO E IPG

\begin{tabular}{|c|c|c|c|c|c|c|c|}
\hline & \multirow{2}{*}{ Curso } & \multirow{2}{*}{ Total } & \multicolumn{2}{|c|}{ Homens } & \multicolumn{2}{|c|}{ Mulheres } & \multirow{2}{*}{ IPG } \\
\hline & & & Ranking & Obs. & Ranking & Obs. & \\
\hline & Total de estudantes & 2.694 .245 & & 1.178 .893 & & 1.515 .352 & 1,29 \\
\hline & Subtotal nos 20 cursos mais frequentes & 1.809 .529 & & 757.216 & & 1.052 .313 & 1,39 \\
\hline 1 & Direito & 369.777 & 1 & 187.559 & 2 & 182.218 & 0,97 \\
\hline 2 & Administração & 290.264 & 2 & 159.082 & 3 & 131.182 & 0,82 \\
\hline 3 & Pedagogia & 202.584 & 18 & 14.538 & 1 & 188.046 & 12,93 \\
\hline 4 & Ciências Contábeis & 126.616 & 3 & 66.467 & 5 & 60.149 & 0,90 \\
\hline 5 & Letras - Licenciatura & 104.575 & 15 & 17.395 & 4 & 87.180 & 5,01 \\
\hline 6 & Comunicação Social (redação e conteúdo) & 79.584 & 7 & 32.191 & 7 & 47.393 & 1,47 \\
\hline 7 & Economia & 65.414 & 5 & 38.756 & 11 & 26.658 & 0,69 \\
\hline 8 & Psicologia & 59.612 & 33 & 8.128 & 6 & 51.484 & 6,33 \\
\hline 9 & Fisioterapia & 55.609 & 20 & 13.452 & 8 & 42.157 & 3,13 \\
\hline 10 & Medicina & 54.812 & 8 & 29.712 & 12 & 25.100 & 0,84 \\
\hline 11 & Ciência da Computação & 52.336 & 4 & 39.382 & 27 & 12.954 & 0,33 \\
\hline 12 & Odontologia & 46.184 & 16 & 17.123 & 9 & 29.061 & 1,70 \\
\hline 13 & Educação Física - Licenciatura & 45.257 & 10 & 23.687 & 20 & 21.570 & 0,91 \\
\hline 14 & Engenharia Civil & 42.173 & 6 & 32.257 & 33 & 9.916 & 0,31 \\
\hline 15 & Arquitetura e Urbanismo & 37.162 & 19 & 13.621 & 15 & 23.541 & 1,73 \\
\hline 16 & História - Licenciatura & 37.106 & 22 & 13.264 & 14 & 23.842 & 1,80 \\
\hline 17 & Matemática - Licenciatura & 36.686 & 17 & 16.945 & 21 & 19.741 & 1,17 \\
\hline 18 & Ciências - Licenciatura & 36.071 & 24 & 12.579 & 16 & 23.492 & 1,87 \\
\hline 19 & Turismo & 33.916 & 28 & 9.933 & 13 & 23.983 & 2,41 \\
\hline 20 & Farmácia & 33.791 & 26 & 11.145 & 17 & 22.646 & 2,03 \\
\hline
\end{tabular}

Fonte: Elaboração dos autores com base nos microdados do Censo da Educação Superior de 2000.

Dentre os 20 cursos mais frequentes, os valores mais extremos do IPG são observados para os cursos de Pedagogia $(12,93)$ e Engenharia Civil $(0,31)$. No caso de Pedagogia, nota-se que, apesar de ser o terceiro curso com mais alunos matriculados no ano de 2000, é apenas o 18으 mais frequente entre a população masculina, ao passo que, para as mulheres, é o primeiro. O IPG indica que, para cada homem matriculado em Pedagogia, há 12,93 mulheres. Padrão semelhante é verificado nos cursos de Psicologia e Letras - Licenciatura, cujos IPG são, respectivamente, 6,33 e 5,01.

Em se tratando de Engenharia Civil, ocorre o contrário: apesar de ser o $14^{\circ}$ curso no ranking geral, é o sexto com maior frequência de homens, ao mesmo tempo em que ocupa apenas a 33르 posição no ranking feminino. Com isso, para cada homem matriculado, tem-se apenas 0,31 mulher matriculada. $\mathrm{O}$ padrão se repete para os cursos de Ciência da Computação e Economia, com IPG de, respectivamente, 0,33 e 0,69, indicando acentuada disparidade em favor dos homens.

Há, ainda, cursos com IPG relativamente próximos de 1 , ou seja, que se aproximam de uma paridade por sexo. São eles Direito (0,97), Educação Física - Licenciatura (0,91), Ciências Contábeis $(0,90)$ e Matemática - Licenciatura $(1,17)$.

A Tabela 3 replica a mesma análise para a edição de 2017 do Censo da Educação Superior, a qual contava com 329 cursos presenciais ${ }^{5}$ e 6,49 milhões de alunos matriculados - um salto de 
aproximadamente $141 \%$ em relação a $2000 .{ }^{6}$ O número de mulheres aumentou $138 \%$, e passou a totalizar 3,60 milhões de indivíduos, o que representava 55,5\% dos estudantes matriculados. Assim, houve uma ligeira redução na proporção feminina - de 0,7 ponto percentual. Tal redução se refletiu no IPG geral, que declinou de 1,29 para 1,24. Essa taxa, no entanto, não reflete o comportamento do nível de segregação nos cursos, que é captado pelas medidas a serem apresentadas mais adiante neste trabalho.

\section{TABELA 3}

DISTRIBUIÇÃO DE ESTUDANTES DE GRADUAÇÃO PRESENCIAL, NOS 20 CURSOS MAIS FREQUENTES, POR SEXO E IPG

\begin{tabular}{|c|c|c|c|c|c|c|c|}
\hline & Curco & Tata & & nens & & ieres & IDF \\
\hline & Curso & lotal & Ranking & Obs. & Ranking & Obs. & IPG \\
\hline & Total de estudantes & 6.494 .098 & & 2.892 .830 & & 3.601 .268 & 1,24 \\
\hline & Subtotal nos 20 cursos mais frequentes & 4.405 .516 & & 1.848 .733 & & 2.556 .783 & 1,38 \\
\hline 1 & Direito & 878.940 & 1 & 392.620 & 1 & 486.320 & 1,24 \\
\hline 2 & Administração & 481.768 & 3 & 221.713 & 2 & 260.055 & 1,17 \\
\hline 3 & Engenharia Civil & 335.029 & 2 & 231.815 & 10 & 103.214 & 0,45 \\
\hline 4 & Enfermagem & 285.097 & 17 & 45.317 & 4 & 239.780 & 5,29 \\
\hline 5 & Pedagogia & 284.230 & 29 & 24.183 & 3 & 260.047 & 10,75 \\
\hline 6 & Psicologia & 249.956 & 16 & 48.842 & 5 & 201.114 & 4,12 \\
\hline 7 & Ciências Contábeis & 244.840 & 5 & 106.876 & 6 & 137.964 & 1,29 \\
\hline 8 & Arquitetura e Urbanismo & 167.536 & 13 & 55.966 & 8 & 111.570 & 1,99 \\
\hline 9 & Fisioterapia & 163.791 & 20 & 34.359 & 7 & 129.432 & 3,77 \\
\hline 10 & Medicina & 149.655 & 11 & 62.533 & 12 & 87.122 & 1,39 \\
\hline 11 & Engenharia de Produção & 141.315 & 6 & 89.444 & 18 & 51.871 & 0,58 \\
\hline 12 & Engenharia Mecânica & 130.407 & 4 & 116.947 & 41 & 13.460 & 0,12 \\
\hline 13 & Farmácia & 126.892 & 19 & 35.580 & 11 & 91.312 & 2,57 \\
\hline 14 & Educação Física - Bacharelado & 126.680 & 8 & 82.680 & 20 & 44.000 & 0,53 \\
\hline 15 & Nutrição & 124.885 & 34 & 18.326 & 9 & 106.559 & 5,81 \\
\hline 16 & Odontologia & 115.706 & 22 & 32.189 & 13 & 83.517 & 2,59 \\
\hline 17 & Educação Física - Licenciatura & 111.294 & 9 & 67.175 & 19 & 44.119 & 0,66 \\
\hline 18 & Engenharia Elétrica & 102.954 & 7 & 88.737 & 39 & 14.217 & 0,16 \\
\hline 19 & Medicina Veterinária & 93.650 & 23 & 30.685 & 14 & 62.965 & 2,05 \\
\hline 20 & Agronomia & 90.891 & 10 & 62.746 & 26 & 28.145 & 0,45 \\
\hline
\end{tabular}

Fonte: Elaboração dos autores com base nos microdados do Censo da Educação Superior de 2017.

Em 2017, o ranking dos 20 cursos mais frequentes sofreu alterações, apesar de alguns deles, como Direito, Administração, Fisioterapia e Medicina, terem mantido suas posições relativas. Uma variação que merece destaque é a do curso de Engenharia Civil, que, em 2000, ocupava a $14^{a}$ posição

6 O aumento no número de matriculados é explicado pela expansão no número de vagas ofertadas ocorrida principalmente na década de 2000. Apesar de o processo de expansão do ensino superior ter se iniciado na década de 1990, ele foi mais expressivo a partir do Governo Lula, período em que o Estado assumiu o papel de agente indutor de políticas de expansão universitária no país, gerando um incremento substancial na oferta de vagas, bem como no número de estudantes matriculados, tanto em instituições privadas quanto públicas (Pereira \& Silva, 2010). Entre as medidas postas em prática no período, destaca-se o Programa de Apoio a Planos de Reestruturação e Expansão das Universidades Federais (Reuni), que teve como principal objetivo aumentar a oferta de vagas nas universidades federais, possibilitando sua expansão física, acadêmica e pedagógica. Na esfera do ensino privado, destaca-se o Programa Universidade para Todos (Prouni), que concedeu bolsas de estudo parciais e integrais em instituições privadas de ensino superior para estudantes de baixa renda. Além desses programas, houve também a reestruturação do já existente Programa de Financiamento Estudantil (Fies), com expansão na oferta de linhas de crédito para o financiamento dos estudos em instituições privadas do ensino superior. 
no ranking geral e passou a ocupar o 3 ํ lugar em 2017. Nesse curso, houve um incremento significativo no número total de matriculados, da ordem de $694 \%$. Como o crescimento no número de mulheres (941\%) foi maior que no de homens (619\%), o IPG aumentou de 0,31 para 0,45 - o que ainda indica, no entanto, uma disparidade alta em favor dos homens.

Em seu estudo, Barreto (2014) discorre sobre a participação feminina nos cursos de engenharia no Brasil. A autora destaca o crescimento notável do número de mulheres matriculadas nas engenharias entre 1971 e 2011. No entanto, ressalva que elas ainda são minoria nessas áreas, tanto em posições de liderança como em pesquisas, destacando o preconceito e a discriminação enfrentados.

A predominância de homens nas engenharias, apesar do crescimento da parcela feminina, também é analisada por Martins (2018), que constata a segregação no ensino superior, bem como no mercado de trabalho, em que se verificam diferenças na empregabilidade e nos salários, devido à reprodução de preconceitos e estereótipos sexistas frequentes na área.

Esse argumento também é explorado por Lombardi (2008), que, ao realizar entrevistas com engenheiros e engenheiras que desempenharam, em algum momento, funções de alta gerência, encontrou diferentes padrões de ascensão na carreira. Para os engenheiros, é frequente a ascensão linear na hierarquia dos postos, seguindo indicações e colaboração com outros homens. A carreira das engenheiras, por sua vez, tende a seguir uma trajetória não linear, com períodos de estagnação alternados com impulsos abruptos, sendo raras as indicações e cooptações. A autora identifica diversos obstáculos enfrentados pelas mulheres nessa área ao buscarem cargos altos, como a falta de reconhecimento de suas habilidades e do trabalho executado, a associação preconceituosa a atividades consideradas femininas no ambiente de trabalho - como a necessidade de servir aos homens -, estereótipos de gênero e as dificuldades para conciliar a vida profissional com a família e os filhos, cuja responsabilidade costuma recair sobre a mulher. Lombardi (2008) cita, ainda, a importância dos chamados "clubinhos masculinos", referindo-se às relações de convivência entre os homens de uma empresa, que discutem entre si não apenas assuntos informais, mas também questões relacionadas ao trabalho, e normalmente acabam excluindo as mulheres.

Conforme se vê, as dificuldades que as mulheres podem enfrentar nas Engenharias de modo geral, bem como a construção social que as condiciona a escolherem carreiras de cunho menos técnico e competitivo e mais voltadas ao cuidado com os outros, são fatores que podem explicar sua menor participação nessas áreas. Por introjetarem as normas e estereótipos de gênero e, em paralelo, terem poucos exemplos nos quais se espelhar, as estudantes são pouco propensas a escolherem as Engenharias e demais carreiras STEM no ensino superior.

Ainda no comparativo entre 2000 e 2017, percebe-se que houve uma redução nos IPG dos cursos de Pedagogia e Psicologia, que passaram a 10,75 e 4,12, respectivamente. Ainda assim, Pedagogia continua sendo o curso de maior IPG no ranking dos 20 cursos mais frequentes, embora tenha deixado de ser o mais procurado pelas mulheres, sendo suplantado por Direito e Administração, ambos com IPG relativamente próximos de 1 (1,24 e 1,17, respectivamente).

A análise conjunta das tabelas 2 e 3 permite concluir, portanto, que, no comparativo entre 2000 e 2017, houve redução na disparidade por sexo nos cursos com níveis de segregação mais extremos entre os mais populosos. Porém, essa evolução caminha a passos lentos. Uma projeção linear para o curso de Engenharia Civil indica que, a esse ritmo, a paridade plena no nú mero de matriculados ocorrerá apenas em 2084. No curso de Pedagogia, esse cenário somente será possível em 2093.

A Tabela 4, a seguir, traz a porcentagem de mulheres nas 22 áreas específicas da classificação adotada pelo Inep (2018) nos anos de 2000 e 2017. Mais uma vez evidencia-se a existência de áreas com predominância masculina, tais como Engenharia e profissões correlatas e Computação, bem como áreas mais ocupadas por mulheres, com destaque para Serviço Social e Formação de Professores e Ciências da Educação. Deve ser feita, contudo, uma ressalva a respeito das análises que utilizam a classificação 
por área específica, uma vez que ela agrega cursos com níveis muito distintos de participação feminina, encobrindo o verdadeiro grau de disparidade de gênero observado. Um exemplo desse fato se dá na área de Saúde, que, em 2017, contava com 71,6\% de mulheres. No entanto, ao desagregá-la por cursos, verificavam-se diferenças importantes: em Educação Física, apenas 34,7\% dos estudantes matriculados eram mulheres, ao passo que, em Enfermagem, esse percentual era de $84,1 \%$.

\section{TABELA 4}

PERCENTUAL DE MULHERES (\%) MATRICULADAS NO ENSINO SUPERIOR PRESENCIAL, SEGUNDO REGIÃO E ÁREA ESPECÍFICA DO CURSO

\begin{tabular}{|c|c|c|c|c|c|c|c|c|c|c|c|c|}
\hline \multirow[b]{2}{*}{ Área do curso } & \multicolumn{6}{|c|}{2000} & \multicolumn{6}{|c|}{2017} \\
\hline & $\begin{array}{l}\text { Centro- } \\
\text {-Oeste }\end{array}$ & $\begin{array}{l}\text { Nor- } \\
\text { deste }\end{array}$ & Norte & $\begin{array}{l}\text { Su- } \\
\text { deste }\end{array}$ & Sul & Brasil & $\begin{array}{l}\text { Centro- } \\
\text {-Oeste }\end{array}$ & $\begin{array}{l}\text { Nor- } \\
\text { deste }\end{array}$ & Norte & $\begin{array}{l}\text { Su- } \\
\text { deste }\end{array}$ & Sul & Brasil \\
\hline $\begin{array}{l}\text { Agricultura, } \\
\text { florestas e recursos } \\
\text { pesqueiros }\end{array}$ & 31,6 & 34,0 & 45,2 & 29,1 & 27,6 & 31,3 & 35,8 & 44,6 & 47,3 & 35,5 & 33,3 & 37,8 \\
\hline $\begin{array}{l}\text { Arquitetura e } \\
\text { construção }\end{array}$ & 43,0 & 35,6 & 39,0 & 43,4 & 45,6 & 42,2 & 41,8 & 40,1 & 38,2 & 43,1 & 46,3 & 42,6 \\
\hline Artes & 61,6 & 49,9 & 34,8 & 57,5 & 60,2 & 57,5 & 61,1 & 57,9 & 51,7 & 55,8 & 62,7 & 57,9 \\
\hline Ciências & 69,7 & 62,8 & 61,5 & 67,3 & 72,7 & 67,6 & 71,3 & 70,1 & 69,9 & 74,8 & 76,0 & 73,3 \\
\hline Ciências físicas & 44,7 & 35,0 & 42,5 & 39,2 & 46,7 & 40,7 & 47,0 & 34,7 & 48,8 & 41,9 & 48,6 & 41,3 \\
\hline $\begin{array}{l}\text { Ciências sociais e } \\
\text { comportamentais }\end{array}$ & 63,7 & 57,6 & 58,5 & 66,3 & 62,3 & 63,4 & 73,5 & 73,2 & 70,5 & 71,0 & 70,9 & 71,6 \\
\hline Computação & 31,1 & 24,3 & 32,1 & 28,0 & 24,6 & 27,5 & 13,2 & 12,7 & 15,1 & 13,9 & 11,7 & 13,4 \\
\hline $\begin{array}{l}\text { Comércio e } \\
\text { administração }\end{array}$ & 50,8 & 46,8 & 52,6 & 47,0 & 45,8 & 47,3 & 54,0 & 53,1 & 55,1 & 56,0 & 54,3 & 54,9 \\
\hline Direito & 51,0 & 46,3 & 48,7 & 49,7 & 48,4 & 49,3 & 55,6 & 52,3 & 53,4 & 56,7 & 56,3 & 55,3 \\
\hline $\begin{array}{l}\text { Engenharia } \\
\text { e profissões } \\
\text { correlatas }\end{array}$ & 15,2 & 16,7 & 22,4 & 15,4 & 14,2 & 15,5 & 24,6 & 27,3 & 27,9 & 24,8 & 22,9 & 24,9 \\
\hline $\begin{array}{l}\text { Formação de } \\
\text { professor e ciências } \\
\text { da educação }\end{array}$ & 75,7 & 70,6 & 70,3 & 79,8 & 79,8 & 76,5 & 67,9 & 62,2 & 60,1 & 69,2 & 67,0 & 65,6 \\
\hline $\begin{array}{l}\text { Humanidades e } \\
\text { letras }\end{array}$ & 64,1 & 55,7 & 56,3 & 70,3 & 65,8 & 66,6 & 47,6 & 42,8 & 35,6 & 49,2 & 41,5 & 46,3 \\
\hline $\begin{array}{l}\text { Jornalismo e } \\
\text { informação }\end{array}$ & 63,6 & 62,7 & 56,6 & 59,8 & 61,6 & 60,6 & 60,7 & 58,8 & 61,3 & 60,2 & 61,4 & 60,2 \\
\hline $\begin{array}{l}\text { Matemática e } \\
\text { estatística }\end{array}$ & 41,2 & 30,7 & 31,8 & 45,0 & 54,0 & 42,8 & 34,3 & 32,7 & 41,0 & 36,2 & 35,7 & 35,5 \\
\hline $\begin{array}{l}\text { Produção e } \\
\text { processamento }\end{array}$ & 72,5 & 51,3 & 63,6 & 47,0 & 57,3 & 53,7 & 64,5 & 56,5 & 56,9 & 55,3 & 64,8 & 58,3 \\
\hline Proteção ambiental & - & - & - & 33,9 & - & 33,9 & 51,6 & 60,2 & 55,1 & 55,2 & 55,4 & 55,8 \\
\hline Saúde & 73,5 & 67,8 & 64,4 & 68,2 & 68,5 & 68,4 & 72,6 & 72,4 & 71,1 & 71,2 & 70,9 & 71,6 \\
\hline Serviço social & 94,0 & 96,4 & 92,1 & 94,9 & 95,7 & 95,2 & 89,1 & 91,3 & 89,5 & 88,2 & 87,5 & 89,6 \\
\hline $\begin{array}{l}\text { Serviços de } \\
\text { segurança }\end{array}$ & - & 19,0 & - & 17,5 & 0,0 & 16,1 & 30,4 & 44,7 & 50,4 & 18,3 & 0,0 & 31,8 \\
\hline $\begin{array}{l}\text { Serviços de } \\
\text { transportes } \\
\text { (cursos gerais) }\end{array}$ & 0,0 & - & - & 9,4 & 11,3 & 9,8 & 9,5 & 19,3 & - & 22,8 & 16,6 & 20,1 \\
\hline Serviços pessoais & 71,6 & 71,7 & 75,0 & 71,3 & 69,2 & 71,1 & 80,4 & 72,8 & 80,5 & 76,8 & 78,7 & 76,7 \\
\hline Veterinária & 46,9 & 49,9 & 48,3 & 57,0 & 50,4 & 53,3 & 61,7 & 62,3 & 61,3 & 70,1 & 67,9 & 67,2 \\
\hline Total & 58,8 & 56,8 & 57,3 & 55,5 & 56,4 & 56,2 & 56,4 & 57,0 & 56,4 & 54,9 & 53,9 & 55,5 \\
\hline
\end{tabular}

Fonte: elaboração própria com base nos microdados do Censo da Educação Superior de 2000 e 2017. 
A última linha da Tabela 4 apresenta a porcentagem de mulheres matriculadas segundo região do país, em 2000 e em 2017. Em ambos os anos, essa taxa gravitou em torno da média nacional para todas as regiões, não havendo, dessa forma, indícios de grandes heterogeneidades regionais.

A comparação intertemporal permite inferir que a segregação por sexo nas áreas específicas persistiu com o passar dos anos. À exceção de Humanidades e Letras, as áreas predominantemente femininas - ou seja, com ao menos $60 \%$ de mulheres - seguiam nessa condição em 2017. Na metade delas a proporção de mulheres aumentou ainda mais, a saber: Ciências (de 67,6\% para 73,3\%), Ciências Sociais e Comportamentais (de 63,4\% para 71,6\%), Saúde (de 68,4\% para 71,6\%) e Serviços Pessoais (de 71,1\% para 76,7\%). Por outro lado, entre as seis áreas predominantemente masculinas, isto é, com menos de $40 \%$ de mulheres, apenas uma mudou de situação em 2017, tornando-se integrada - situação em que a proporção feminina se encontra entre $40 \%$ e $60 \%$.

Entre as áreas que, em 2000, eram consideradas integradas, houve um aumento da proporção de mulheres, à exceção de Matemática e Estatística, que passou a masculina. Merece destaque a área de Computação, em que a proporção feminina declinou de 27,5\%, em 2000, para 13,4\%, em 2017. Esse comportamento foi observado em todas as regiões do país. A literatura aponta, entretanto, que as mulheres tiveram papel fundamental na origem dos primeiros computadores, e que sua participação na área foi frequentemente omitida pela historiografia, o que contribuiu para perpetuar a percepção equivocada de que essa área sempre foi dominada pelos homens e de que as mulheres são desinteressadas ou incapazes (Light, 1999). Tanto na Ciência da Computação como em outras áreas STEM, há evidências de um efeito retroalimentativo, segundo o qual a sub-representação feminina e a omissão de role models, isto é, de exemplos de mulheres bem-sucedidas, desencorajam as meninas a seguirem essas carreiras (Emerson et al., 2012; Shin et al., 2016; González-Pérez et al., 2020).

$\mathrm{Na}$ área de Direito, a proporção de mulheres saltou de 49,3\%, em 2000, para 55,3\%, em 2017. Em Jornalismo e Informação, esse percentual oscilou de 60,6\% para 60,2\%.É relevante ressaltar, porém, que os obstáculos enfrentados pelas mulheres não são necessariamente eliminados nas áreas em que elas são ou se tornaram maioria, persistindo a posteriori, no mercado de trabalho, o fenômeno do "teto de vidro". Essa expressão é utilizada para designar as barreiras invisíveis que dificultam e retardam a ascensão das mulheres a cargos de comando nas organizações, gerando uma sub-representação feminina no topo das hierarquias.

Ao tratar da trajetória de carreira das advogadas atuantes nos melhores escritórios brasileiros, Bertolin (2017) observa a existência do teto de vidro nas sociedades de advogados, uma vez que, mesmo com condições semelhantes para ambos os sexos, os homens têm maior probabilidade de se tornarem sócios de escritórios (isto é, o cargo mais alto da hierarquia dessas organizações), de modo que a população feminina se concentra mais na base da carreira. Segundo a autora, "não houve adequação da profissão ao ingresso maciço de mulheres ocorrido nas últimas décadas” (Bertolin, 2017, p. 25). Situação semelhante é observada no Jornalismo, em que o maior número de mulheres não é acompanhado de uma representação proporcional desse sexo nas altas posições das hierarquias profissionais (Leite, 2017).

\section{Análise da segregação}

A Tabela 5 traz os valores dos índices sintéticos de segregação para os anos de 2000 e 2017. O cálculo foi realizado considerando-se os quatro possíveis níveis de agregação dos cursos, a saber: Área Geral, que corresponde ao primeiro dígito da classificação e agrega os cursos em oito grupamentos; ${ }^{7}$ Área Específica, indicada pelos dois primeiros dígitos, e que considera 22 grupos; Área Detalhada, indicada pelos três primeiros dígitos, com 75 categorias observadas, em 2000, e 77, em 2017; e Curso, com 359 possibilidades, em 2000, e 329, em 2017. 
TABELA 5

ÍNDICES DE DISSIMILARIDADE, DE GINI E RAIZ QUADRADA, CONFORME DIFERENTES NÍVEIS DE AGREGAÇÃO DOS CURSOS

\begin{tabular}{lcccccc}
\hline \multicolumn{1}{r}{ Nível de agregação } & \multicolumn{2}{c}{ Índice de dissimilaridade } & \multicolumn{2}{c}{ Índice de Gini } & \multicolumn{2}{c}{ Índice raiz quadrada } \\
& 2000 & 2017 & 2000 & 2017 & 2000 & 2017 \\
\hline Área Geral & 0,2659 & 0,2219 & 0,3430 & 0,2990 & 0,0513 & 0,0389 \\
Área Específica & 0,2965 & 0,2499 & 0,3864 & 0,3584 & 0,0666 & 0,0597 \\
Área Detalhada & 0,3426 & 0,3031 & 0,4676 & 0,4626 & 0,1055 & 0,1024 \\
\hline Curso & 0,3586 & 0,3353 & 0,4874 & 0,4952 & 0,1165 & 0,1129 \\
\hline
\end{tabular}

Fonte: Elaboração dos autores com base nos microdados do Censo da Educação Superior de 2000 e 2017.

Conforme se vê, quanto maior o nível de agregação adotado, menor é o grau de segregação aferido, independentemente do índice. Isso ocorre porque a agregação de cursos em uma determinada categoria baseia-se na proximidade do conhecimento, e não na participação de mulheres. Assim, podem ser reunidos em um mesmo grupo cursos muito distintos no que tange à representação feminina, encobrindo, dessa maneira, parte da disparidade de gênero. Vale notar que essa sensibilidade das medidas de segregação ao grau de agregação das unidades de análise - sejam elas cursos universitários, ocupações, etc. - é de conhecimento na literatura, conforme explica Anker (1998, p. 96). Para aferir de modo apropriado o grau de segregação, recomenda-se que a análise seja realizada com base em classificações de três ou mais dígitos, ou seja, mais detalhadas, já que os dados de um e dois dígitos - mais agregados - costumam ser insuficientemente detalhados (Degraff \& Anker, 2004, p. 191). Assim, este trabalho enfoca os resultados obtidos ao se considerarem as classificações segundo Área Detalhada e Curso.

Nota-se que o índice de dissimilaridade apresentou redução entre 2000 e 2017. Seu valor, considerando a classificação em Área Detalhada, em 2017, indica que 30,3\% dos estudantes de um determinado sexo deveriam mudar de área (tanto por meio do movimento de homens em direção a áreas mais femininas, como de mulheres em direção a áreas mais masculinas) para que a segregação fosse eliminada. Em 2000, esse valor era de 34,3\% (uma redução de 11,5\%, portanto). Na classificação por Curso, o índice de dissimilaridade passou de 35,9\%, em 2000, para 33,5\%, em 2017 (redução de 6,5\%). A comparação revela, portanto, que quanto mais desagregada a classificação adotada, não apenas é maior o índice de dissimilaridade, como também menor a sua redução intertemporal.

Em se tratando do índice de Gini - que, conforme explicado na seção metodológica, é uma medida que satisfaz propriedades desejáveis de uma medida de segregação -, a comparação intertemporal, ao se considerar a classificação por Curso, revela não ter havido redução no nível de segregação por sexo. Essa medida, pelo contrário, elevou-se, passando de 0,487, em 2000, para 0,495, em 2017 - um aumento de 1,6\%. A Figura 2 apresenta a curva de segregação para 2000 e 2017, que serve como suporte de análise ao se utilizar o índice de Gini. 


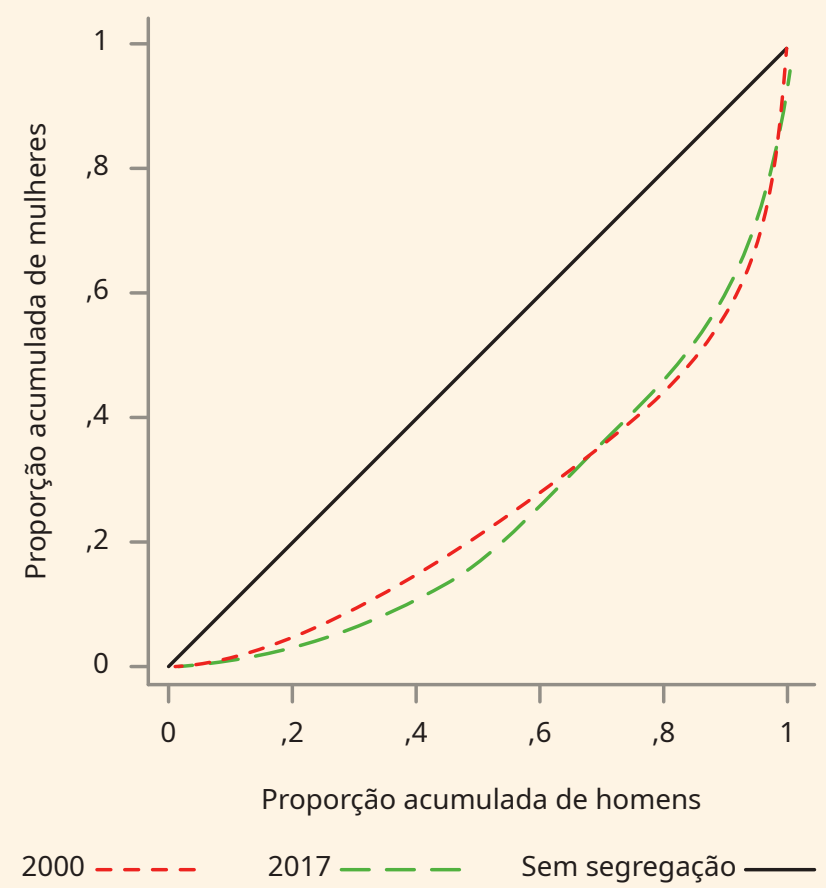

Fonte: Elaboração dos autores com base nos microdados do Censo da Educação Superior de 2000 e 2017.

Assim, ao nível mais desagregado de análise, embora o índice de dissimilaridade tenha apresentado evidências de redução na segregação por sexo ao longo do período analisado, uma análise mais apurada pautada no cálculo do índice de Gini mostrou tendência oposta, de aumento da segregação. Essa aparente contradição nos resultados pode ser explicada pelo fato de o índice de dissimilaridade captar variações no nível de segregação decorrentes apenas da transição de indivíduos de um curso majoritariamente feminino para outro masculino (ou vice-versa), ao passo que o índice de Gini é sensível a qualquer alteração na composição por sexo das categorias analisadas que resulte em redução ou aumento da segregação por sexo.

Os resultados obtidos com base no índice raiz quadrada, por seu turno, corroboram aqueles encontrados para o índice de dissimilaridade, mostrando queda na segregação, porém em menor magnitude: de 2,9\%, quando considerada a classificação conforme Áreas Detalhadas, e de 3,1\%, em se tratando da classificação por Curso.

Uma propriedade interessante do índice raiz quadrada, conforme explicado anteriormente, é que ele pode ser decomposto na segregação observada entre grupos de cursos semelhantes (quanto à área de conhecimento) e na segregação observada nesses grupos. A Tabela 6 apresenta o resultado dessa decomposição quando a segregação medida ao nível mais desagregado (isto é, ao nível do Curso) é decomposta de acordo com os três tipos de agrupamentos possíveis: por Área Geral, por Área Específica e por Área Detalhada. 
TABELA 6

DECOMPOSIÇÃO DA SEGREGAÇÃO TOTAL (MEDIDA AO NÍVEL DE CURSO) CONSIDERANDO AS ÁREAS GERAL, ESPECÍFICA E DETALHADA

\begin{tabular}{|c|c|c|c|c|c|c|}
\hline \multirow{2}{*}{ Nível de agregação } & \multicolumn{3}{|c|}{2000} & \multicolumn{3}{|c|}{2017} \\
\hline & Entre & Dentro & Total & Entre & Dentro & Total \\
\hline \multicolumn{7}{|l|}{ Área geral } \\
\hline Índice raiz quadrada & 0,051 & 0,065 & 0,116 & 0,039 & 0,074 & 0,113 \\
\hline Participação (\%) & 44,1 & 55,9 & 100,0 & 34,5 & 65,5 & 100,0 \\
\hline \multicolumn{7}{|l|}{ Área específica } \\
\hline Índice raiz quadrada & 0,067 & 0,050 & 0,116 & 0,060 & 0,053 & 0,113 \\
\hline Participação (\%) & 57,2 & 42,8 & 100,0 & 52,9 & 47,1 & 100,0 \\
\hline \multicolumn{7}{|l|}{ Área detalhada } \\
\hline Índice raiz quadrada & 0,105 & 0,011 & 0,116 & 0,102 & 0,010 & 0,113 \\
\hline Participação (\%) & 90,6 & 9,4 & 100,0 & 90,8 & 9,2 & 100,0 \\
\hline
\end{tabular}

Fonte: Elaboração dos autores com base nos microdados do Censo da Educação Superior de 2000 e 2017.

Conforme apresentado na Tabela 5, a segregação considerando Cursos, segundo o índice raiz quadrada, diminuiu 3,1\% entre 2000 e 2017 (redução de 0,116 para 0,113). Ao agrupar os Cursos segundo as Áreas Gerais, verificou-se redução do componente entre grupamentos, com a participação desse termo na segregação total declinando de 44,1\% para 34,5\%. Nas Áreas Gerais, entretanto, a segregação aumentou (passando de 0,065 para 0,074 ). Desse modo, a queda no grau geral de segregação foi impulsionada pela redistribuição de homens e mulheres entre as oito grandes áreas de conhecimento, já que, nelas, a estratificação por sexo au mentou. Resultado similaréobtido considerando a decomposição conforme as Áreas Específicas. Nesse caso, a participação do componente entre grupos na segregação total diminuiu de 57,2\% para 52,9\%. Em se tratando da decomposição conforme Área Detalhada, não há mudança importante nos componentes entre e nos grupos, o que sugere que essa forma de agregação dos cursos segundo proximidade do conhecimento não encobre de modo substancial o verdadeiro grau de disparidade de gênero observado.

Assim, há dois resultados principais que podem ser extraídos da análise conduzida nesta seção. Primeiro, há evidência de queda no grau geral de segregação entre 2000 e 2017. Porém, uma análise rigorosa desse comportamento, à luz de indicadores mais robustos e com base em uma classificação mais desagregada dos cursos, indica ligeiro aumento (segundo o índice de Gini) ou queda muito tímida (segundo o índice raiz quadrada) da segregação. Assim, análises pautadas apenas no cálculo do índice de dissimilaridade - o mais difundido na literatura - com base na classificação de um ou dois dígitos podem conduzir a resultados falaciosos a respeito da evolução da segregação, sugerindo um cenário mais promissor do que o observado de fato. Em segundo lugar, a análise de decomposição do índice raiz quadrada mostrou que a queda no grau geral de segregação foi impulsionada pela integração por sexo das grandes áreas de conhecimento - processo parcialmente contrabalançado pelo aumento da segregação nelas.

\section{Considerações finais}

O propósito desta pesquisa foi analisar a segregação por sexo nos cursos presenciais do ensino superior brasileiro, observando, em âmbito nacional, a evolução desse fenômeno, tomando como referência os anos de 2000 e 2017. Esse tema se justifica porque, apesar de ter ocorrido uma reversão no hiato de gênero no ensino superior, com as mulheres tornando-se maioria no ambiente universitário, não há igualdade em sua representatividade nos diferentes cursos. Em particular, os cursos mais prestigiados 
perante a sociedade e que, potencialmente, oferecem maiores retornos no mercado de trabalho continuam apresentando uma predominância masculina.

A análise descritiva preliminar mostrou uma redução da disparidade por sexo nos cursos mais emblemáticos, a saber, Engenharia Civil e Pedagogia, que apresentam grande concentração de homens e de mulheres, respectivamente. No entanto, ainda que ambos caminhem em direção à paridade de gênero, projeções lineares indicam que a igualdade plena somente ocorrerá nas últimas décadas deste século, mostrando, portanto, que o avanço é lento.

Também se observou que as áreas específicas mistas ou integradas, isto é, nas quais as proporções de mulheres e de homens são próximas, apresentam uma tendência a se tornarem mais femininas com o tempo. As evidências na literatura mostram, porém, que, mesmo quando as mulheres são maioria em uma determinada ocupação no mercado de trabalho, as desigualdades de gênero não desaparecem, pois os estereótipos continuam a se refletir nas barreiras enfrentadas para a ascensão na carreira.

A análise conjunta dos índices de dissimilaridade e raiz quadrada indica queda no grau geral de segregação entre 2000 e 2017, quando considerado o nível mais desagregado de análise (cursos). Esse resultado é explicado pela redução da estratificação por sexo entre as grandes áreas de conhecimento, pois nelas a análise de decomposição do índice raiz quadrada aponta que a segregação aumentou.

Em linhas gerais, portanto, os resultados são positivos, trazendo sinais de avanços em termos de equidade de gênero no ambiente universitário. Contudo, duas ressalvas merecem ser feitas. A primeira é que a queda na segregação tem se dado em ritmo lento, haja vista que, no cômputo geral, ela foi de apenas 3,1\%, de acordo com o índice raiz quadrada, em um período de 17 anos. A segunda é que tal resultado, embora positivo, insere-se em um contexto mais amplo de redução na velocidade dos avanços e conquistas das mulheres no mercado de trabalho brasileiro. A taxa de participação feminina, que aumentou de modo vigoroso entre os anos de 1970 e 1990, progrediu mais lentamente nos anos 2000, e apresentou sinais de estabilização nos anos de 2010 - porém, em patamar muito inferior ao observado para os homens -, conforme prenunciavam Soares e Izaki (2002, p. 21). A segregação ocupacional por sexo, por seu turno, aumentou entre 2004 e 2015, revertendo a tendência de queda que vinha sendo relatada na literatura referente a anos anteriores a esse período (Botassio \& Vaz, 2020). Assim, é preciso que pesquisas futuras investiguem com maior detalhamento o ritmo de queda na segregação por sexo nos cursos universitários nas últimas décadas, fazendo uso de séries históricas mais longas, a fim de investigar se a redução na segregação vem se dando em ritmo mais acelerado ou mais lento no período mais recente.

A continuidade das conquistas femininas em direção a uma maior equidade no mercado de trabalho e nos espaços públicos de socialização depende da superação de estereótipos de gênero ainda arraigados na sociedade, que, conforme visto neste trabalho, manifestam-se na escolha profissional. Nesse sentido, é imperioso o fortalecimento de ações e políticas para estimular o ingresso e a permanência das mulheres em cursos predominantemente masculinos no Brasil. Estudos têm mostrado o efeito positivo de role models no ingresso, na permanência e no desempenho das mulheres em carreiras tidas como tipicamente masculinas, como aquelas das áreas STEM. ${ }^{8}$ Assim, redes de apoio e programas de mentoria no ensino médio, firmados em parceria com universidades e empresas, por meio dos quais graduandas e graduadas dessas áreas possam conversar e dar seus depoimentos às adolescentes, podem inspirar essas jovens a escolherem essas carreiras. Adicionalmente, é preciso promover mais ações para

8 Em estudo conduzido na Espanha, González-Pérez et al. (2020) permitiram que mulheres que cursavam ou já haviam cursado a graduação em áreas STEM conversassem com 304 meninas de 12 a 16 anos (isto é, a faixa etária em que as estudantes passam a ter uma percepção negativa de suas próprias habilidades) sobre as possibilidades de carreira. O estudo comprovou que, em média, as meninas que foram expostas a esses exemplos bem-sucedidos se tornaram mais propensas a escolher carreiras nessas áreas do que as que não tiveram contato com esses role models femininos. Um estudo similar foi realizado por Shin et al. (2016) com os role models sendo apresentados aos estudantes por meio da leitura de seis biografias que pudessem inspirá-los. Os resultados indicaram um impacto positivo no interesse por carreiras na área STEM. 
estimular a participação feminina em atividades relacionadas às áreas de ciências e tecnologias no ensino médio - por exemplo, nas Olimpíadas Brasileiras de Matemática, de Física e de Informática e em feiras de ciências -, bem como ampliar a oferta de conteúdos de ciências, tecnologia, engenharia e matemática aos adolescentes.

\section{Referências}

Alves, J. E. D. (1994). Transição da fecundidade e relações de gênero no Brasil [Tese de doutorado, Universidade Federal de Minas Gerais]. Repositório Institucional da UFMG.

Anker, R. (1998). Gender and jobs: Sex segregation of occupations in the world. International Labour Office.

Barreto, A. (2014). A mulher no ensino superior: Distribuição e representatividade. Cadernos do GEA, 3(6), 5-52.

Beltrão, K. I., \& Alves, J. E. D. (2009). A reversão do hiato de gênero na educação brasileira no século XX. Cadernos de Pesquisa, 39(136), 125-156. https://doi.org/10.1590/S0100-15742009000100007

Beltrão, K. I., \& Teixeira, M. D. P. (2005). O vermelho e o negro: Viés de cor e gênero nas carreiras universitárias (Texto para Discussão, 19). Escola Nacional de Ciências Estatísticas.

Bergmann, B. R. (2005). The economic emergence of women. Palgrave Macmillian.

Bertolin, P. T. M. (2017). Feminização da advocacia e ascensão das mulheres nas sociedades de advogados. Cadernos de Pesquisa, 47(163), 16-42. https://doi.org/10.1590/198053143656

Botassio, D. C. (2017). Segregação e desigualdade: Analogia na mensuração e análise da segregação por gênero em setores de atividade no Brasil [Dissertação de mestrado, Universidade de São Paulo]. Biblioteca Digital de Teses e Dissertações da USP. http://doi.org/10.11606/D.11.2017.tde-16082017-090239

Botassio, D. C., \& Vaz, D. V. (2020). Segregação ocupacional por sexo no mercado de trabalho brasileiro: uma análise de decomposição para o período 2004-2015. Revista Brasileira de Estudos de População, 37, e0131. https://doi.org/10.20947/S0102-3098a0131

Chabaud-Rychter, D., \& Gardey, D. (2009). Técnicas e gênero. In H. Hirata, F. Laborie, H. Le Doaré, \& D. Senotier (Orgs.), Dicionário critico do feminismo (pp. 241-246). Editora Unesp.

Degraff, D. S., \& Anker, R. (2004). Gênero, mercados de trabalho e o trabalho das mulheres. In A. Pinnelli (Org.), Gênero nos estudos de população (pp. 163-197). Associação Brasileira de Estudos Populacionais (Abep).

Duncan, O. D., \& Duncan, B. (1955). A methodological analysis of segregation indexes. American Sociological Review, 20(2), 210-217. https://doi.org/10.2307/2088328

Emerson, T. L. N., Mcgoldrick, K., \& Mumford, K. J. (2012). Women and the Choice to Study Economics. The Journal of Economic Education, 43(4), 349-362. https://doi.org/10.1080/00220485.2012.714306

Fresneda, B. (2007). Segregação ocupacional versus discriminação salarial por gênero no mercado de trabalho brasileiro - 2004. In Anais do 13 Congresso Brasileiro de Sociologia.

González-Pérez, S., Cabo, R. M. D., \& Sáinz, M. (2020). Girls in STEM: Is it a female Role-Model Thing? Frontiers in Psichology, 11, 1-21. https://doi.org/10.3389/fpsyg.2020.02204

Herrmann, S. D., Adelman, R. M., Bodford, J. E., Graudejus, O., Okun, M. A., \& Kwan, V. S. Y. (2016). The effects of a female role model on academic performance and persistence of women in STEM courses. Basic and Applied Social Psychology, 38(5), 258-268. https://doi.org/10.1080/01973533.2016.1209757

Hoffmann, R., Botassio, D., \& Jesus, J. G. de (2019). Distribuição de renda: Medidas de desigualdade, pobreza, concentração, segregação e polarização. Edusp.

Hutchens, R. (2001). Numerical measures of segregation: Desirable properties and their implications. Mathematical Social Sciences, 42(1), 13-29. https://doi.org/10.1016/S0165-4896(00)00070-6

Instituto Nacional de Estudos e Pesquisas Educacionais Anísio Teixeira - Inep. (2000). Microdados do Censo da Educação Superior. https://www.gov.br/inep/pt-br/areas-de-atuacao/pesquisas-estatisticas-eindicadores/censo-da-educacao-superior/resultados 
Instituto Nacional de Estudos e Pesquisas Educacionais Anísio Teixeira - Inep. (2017). Microdados do Censo da Educação Superior. https://www.gov.br/inep/pt-br/areas-de-atuacao/pesquisas-estatisticas-eindicadores/censo-da-educacao-superior/resultados

Instituto Nacional de Estudos e Pesquisas Educacionais Anísio Teixeira - Inep. (2018). Manual para classificação de cursos de graduação e sequenciais - CINE Brasil 2018. Inep/MEC. https://download. inep.gov.br/educacao_superior/censo_superior/apresentacao/2018/Manual_Preliminar_para_a_ Classificacao_dos_Cursos_Cine_Brasil_2018.pdf

Jahn, J., Schmid, C. F., \& Schrag, C. (1947). The measurement of ecological segregation. American Sociological Review, 12(3), 293-303. https://doi.org/10.2307/2086519

Kergoat, D. (2009). Divisão sexual do trabalho e relações sociais de sexo. In H. Hirata, F. Laborie, H. Le Doaré, \& D. Senotier (Orgs.), Dicionário crítico do feminismo (pp. 67-75). Editora Unesp.

Leite, A. T. B. (2017). Editoras, repórteres, assessoras e freelancers: Diferenças entre as mulheres no jornalismo. Cadernos de Pesquisa, 47(163), 44-68. http://doi.org/10.1590/198053143810

Light, J. (1999). When computers were women. Technology and Culture, 40(3), 455-483. https://www.jstor. org/stable/25147356

Lombardi, M. R. (2008). Engenheira e gerente: Desafios enfrentados por mulheres em posições de comando na área tecnológica. In A. Costa, B. Sorj, C. Bruschini, \& H. Hirata (Orgs.), Mercado de trabalho e gênero: Comparaçôes internacionais (pp. 387-402). Editora FGV.

Madalozzo, R. (2010). Occupational segregation and the gender wage gap in Brazil: An empirical analysis. Economia Aplicada, 14(2), 147-168. https://doi.org/10.1590/S1413-80502010000200002

Madalozzo, R., \& Artes, R. (2017). Escolhas profissionais e impactos no diferencial salarial entre homens e mulheres. Cadernos de Pesquisa, 47(163), 202-221. http://doi.org/10.1590/198053143666

Martins, V. F. P. (2018). Protagonismo feminino: O gênero como atravessamento para pensar inovação social no Brasil. In Anais do 3 Congresso Nacional de Inovação e Tecnologia - INOVA.

Melo, H. P. de, \& Castilho, M. (2009). Trabalho reprodutivo no Brasil: Quem faz? Revista de Economia Contemporânea, 13(1), 135-158. https://doi.org/10.1590/S1415-98482009000100006

Oliveira, A. M. H. C. (2003). A segregação ocupacional por gênero e seus efeitos sobre os salários no Brasil. In S. Wajnman, \& A. F. Machado (Orgs.), Mercado de trabalho: Uma análise a partir das pesquisas domiciliares no Brasil (pp. 121-149). Editora UFMG.

Pereira, T. I., \& Silva, L. F. S. C. da. (2010). As políticas públicas do ensino superior no governo Lula: Expansão ou democratização? Revista Debates, 4(2), 10-31. https://doi.org/10.22456/19825269.16316

Queiroz, C., Carvalho, M. E., \& Moreira, J. (2014). Gênero e inclusão de jovens mulheres nas ciências exatas, nas engenharias e na computação. In Anais do 18 REDOR - Rede Feminista Norte e Nordeste de Estudos e Pesquisa sobre a Mulher e Relaçôes Gênero. pp. 3483-3500.

Rapoport, B., \& Thibout, C. (2018). Why do boys and girls make different educational choices? The influence of expected earnings and test scores. Economics of Education Review, 62, 205-229. https://doi. org/10.1016/j.econedurev.2017.09.006

Ricoldi, A., \& Artes, A. (2016). Mulheres no ensino superior brasileiro: Espaço garantido e novos desafios. Ex Aequo, 33, 149-161. https://doi.org/10.22355/exaequo.2016.33.10

Shin, J. E. L., Levy, S. R., \& London, B. (2016). Effects of role model exposure on STEM and non-STEM student engagement. Journal of Applied Social Psychology, 46(7), 410-427. https://doi.org/10.1111/ jasp. 12371

Soares, S., \& Izaki, R. S. (2002). A participação feminina no mercado de trabalho (Texto para Discussão, 923). Ipea.

Vaz, D. V., \& Hoffmann, R. (2011). Segregação ocupacional por sexo no setor público brasileiro no período 1995 e 2008. Revista da ABET, 10(1), 120-141. 


\section{Nota sobre autoria}

Maria Fernanda Pessoa: concepção, levantamento e discussão da literatura, discussão teórico-metodológica, estimativa de resultados e análise dos dados; Daniela Verzola Vaz: concepção, orientação, levantamento e discussão da literatura, discussão teórico-metodológica, estimativa de resultados e análise dos dados; Diego Camargo Botassio: discussão teórico-metodológica, estimativa de resultados e análise dos dados.

\section{Disponibilidade de dados}

A rotina computacional para estimativa dos resultados, com base nos microdados do Censo da Educação Superior (Inep, 2000, 2017), está disponível em https://data.scielo.org/dataverse/brcp.

\section{Como citar este artigo}

Pessoa, M. F., Vaz, D. V., \& Botassio, D. C. (2021). Viés de gênero na escolha profissional no Brasil. Cadernos de Pesquisa, 51, Artigo e08400. https://doi.org/10.1590/198053148400 